Porous deproteinized bovine bone scaffold with three-dimensional localized drug delivery system using chitosan microspheres

Li et al. 


\title{
Porous deproteinized bovine bone scaffold with three-dimensional localized drug delivery system using chitosan microspheres
}

\author{
Qing $\mathrm{Li}^{1,2+}$, Gang Zhou ${ }^{3+}$, Xin Yu ${ }^{3}$, Tong Wang ${ }^{2}$, Yuan $\mathrm{Xi}^{3}$ and Zhihui Tang ${ }^{2^{*}}$
}

* Correspondence:
tang_zhihui@live.cn
${ }^{\dagger}$ Equal contributors
${ }^{2}$ National Engineering Laboratory
for Digital and Material Technology
of Stomatology, 22 Zhongguancun
Nandajie, Haidian District, Beijing
100081, China
Full list of author information is
available at the end of the article

\begin{abstract}
Background: Bone substation grafts, such as hydroxyapatite (HA) and tricalciumphosphate (TCP), have been extensively used in clinical applications, but evidence suggests that they offer poor osteoinductive properties compared to allografts and autografts. In order to increase bone growth with such grafts, Bone Morphogenetic Protein 2 (BMP-2) was incorporated into a three dimensional reservoir. The purpose of the present study was to develop a novel drug delivery system which is capable of controlled release of BMP-2.

Methods: DBB were prepared from bovine cancellous bone harvested from fetal bovine femur or tibia and then sinting at $1000^{\circ} \mathrm{C}$. BMP-2-loaded chitosan (CS) microspheres were fabricated by cross-linking. Then the treated DBB powders were blended with chitosan microspheres solution. Finally, the composites were lyophilized with a freeze dryer to obtain the DBB/CMs scaffolds. X-ray diffractor (XRD), scanning electron microscopy (SEM) and Fourier transform infrared (FT-IR) were used to characterize the sample. The quantification of the delivery profile of BMP-2 was determined using an enzyme-linked immunosorbent assay (ELISA) kit. The in vitro assays were to characterize the biocompatibility of this composite.
\end{abstract}

Results: In this study, BMP-2/Chitosan (CS) microspheres were successively loaded onto a deproteinized bovine bone (DBB) scaffold. The release profile of BMP-2 indicated an initial burst release followed by a more even sustained release. An in vitro bioactivity assay revealed that the encapsulated growth factor was biologically active.

Conclusions: The cell culture assay suggest that the excellent biocompatibility of the DBB- BMP-2/CS. Therefore, this novel microsphere scaffold system can be effectively used in current tissue engineering applications.

Keywords: Deproteinized bovine bone (DBB), Scaffold, Microsphere, Drug delivery system

\section{Background}

An increasing number of patients suffer from bone defects that require transplantation [1]. However, bone grafting, the gold standard in bone defect management, bears considerable risks; donor site pain and morbidity, infection, increased blood loss, and longer operating times [2-4]. The most common alternative is to use human cadaveric bone (allograft), which has additional disadvantages, including rejection, limited supply, and potential disease transmission. Interest has thus focused on animal bone (xenograft) that

(c) 2015 Li et al.; licensee BioMed Central. This is an Open Access article distributed under the terms of the Creative Commons Attribution License (http://creativecommons.org/licenses/by/4.0), which permits unrestricted use, distribution, and reproduction in any medium, provided the original work is properly credited. The Creative Commons Public Domain Dedication waiver (http:// creativecommons.org/publicdomain/zero/1.0/) applies to the data made available in this article, unless otherwise stated. 
exhibits physiological and chemical properties similar to autologous bone. But inherent complications with immunogenicity and disease transmission also hinder the effectiveness of this method [5].

For an ideal bone tissue engineering scaffold, one of the most important criteria is that the scaffold consists of a highly interconnected porous network with pore sizes large enough for cell migration, fluid exchange, and eventually tissue ingrowth and vascularization. $\mathrm{Al}$ though synthetic calcium phosphate ceramics (such as $\beta$-tricalciumphosphate ( $\beta$-TCP) [6], and hydroxyapatite (HA) [7]) with their excellent biocompatibility are designed to mimic the native extracellular matrix as closely as possible [8], the porous network of the artificial bone scaffold still cannot compare to natural bone in terms of structure and function.

There is a growing need to provide alternatives to traditional bone grafting. Deproteinized bovine bone (DBB) [9] manufactured from natural materials, such as coral or natural bone, has the advantage of inheriting the properties of the raw source materials, including the pore structure. Because all organic material is removed by stepwise annealing (up to $300^{\circ} \mathrm{C}$ ), there is no need for concern with immunogenicity or disease transmission. Therefore, this kind of inorganic porous bone has gained wide acceptance for various dental and medical applications; e.g. fillers for periodontal defects, alveolar ridge augmentation, maxillofacial reconstruction, dental implants and spine fusion. DBB has been widely used in dentistry as an alternative to autologous bone grafts. Although DBB provides an osteoconductive scaffold, it is not capable of enhancing bone regeneration because it is not osteoinductive.

In addition, during the bone healing process, the constant remodeling activities are coordinated and controlled by various growth factors, such as TGF- $\beta$, PDGF, FGF-2, and BMPs [10]. The osteoinductive capacity of bone morphogenetic proteins (BMPs), especially BMP-2, have been proven to promote osteogenic differentiation [11]. BMP-2 is now approved by the U.S. Food and Drug Administration (FDA) for restricted clinical use in open tibial fractures and anterior spinal fusion. In order to render DBB osteoinductive, bone morphogenetic protein 2 (BMP-2) has previously been incorporated into a three dimensional reservoir (a biomimetic calcium phosphate coating) on $\mathrm{DBB}$, which effectively promoted the osteogenic response by the slow delivery of BMP2. Despite the proven efficacy of BMP, its clinical application is complicated by its short biological half-life, systemic side effects and rapid clearance [12]. Delivery systems that minimize BMP diffusion away from its therapeutic target are desirable not only for enhancing bone formation, but also for limiting unwanted pathologies.

In order to retain the BMPs at the site for a prolonged period of time [13], delivery via microspheres synthesized by chitosan may be used. Chitosan has been widely used for the controlled delivery of peptides or proteins in the form of microspheres, due to its excellent biological properties such as biodegradability, biocompatibility, nontoxicity, bacteriostaticity and strong adhesion [14]. The chitosan used for the synthesis of these microspheres can be both degradable [15] as well as non-degradable [16]. Incorporation of the molecules in these microspheres allows controlled diffusion and exposes the protein molecule for a longer duration.

In this study, deproteinized bovine bone (DBB) and chitosan were chosen as carriers for BMP-2 delivery to overcome the disadvantage of rapid clearance typically associated with BMP-2. Firstly, chitosan microspheres (CMs) loaded with BMP-2 were prepared by an emulsion-ionic cross-linking method. Secondly, CMs with BMP-2 was embedded 
into DBB by a dip-coating process using the capillarity of the material. The purpose of this study was to increase the efficiency of this microsphere-scaffold as a carrier for growth factors and to estimate the osteogenic effect of this microsphere-scaffold as a potential candidate for bone tissue engineering.

\section{Materials and methods}

\section{Preparation of the DBB scaffold}

Samples were prepared from bovine cancellous bone harvested from fetal bovine femur or tibia. Using a diamond saw, the cancellous bones were sectioned into $3 \mathrm{~mm} \times 3 \mathrm{~mm} \times$ $40 \mathrm{~mm}$ blocks. The fatty bone marrow was removed by immersion in $30 \% \mathrm{H}_{2} \mathrm{O}_{2}$ for $2 \mathrm{~h}$. The bone was washed with water and immersed in $1 \% \mathrm{H}_{3} \mathrm{PO}_{4}$ for heating in a water bath at $125^{\circ} \mathrm{C}$ for $2 \mathrm{~h}$. The bone was washed with $95 \%$ alcohol to remove any residual moisture that could cause small cracks during heat treatment. Following air drying for at least $12 \mathrm{~h}$, the bone underwent heat treatment in a furnace (Siliconit muffle furnace, Kwangsung Science Co., Korea) with a heating rate of $10^{\circ} \mathrm{C} / \mathrm{min}$ up to $1000^{\circ} \mathrm{C}$. This temperature was maintained steady for $2 \mathrm{~h}$ under $1 \mathrm{~atm}$ of pressure. To obtain constant size particles of $0.25-1 \mathrm{~mm}$ and 1-2 $\mathrm{mm}$, a sieve with corresponding mesh size was used. After ultrasonic cleaning and drying, the deproteinized bovine bones were obtained.

\section{Preparation of BMP-2 loaded chitosan microspheres}

BMP-2-loaded chitosan (CS) microspheres were fabricated by cross-linking. Briefly, CS polymer with a viscosity of $150-900 \mathrm{cP}$ and $75-85 \%$ deacetylation was purchased from Sigma-Aldrich (Shanghai, China), and then refined twice by dissolving in aqueous acetic acid solution and precipitating from dilute ammonia. The BMP-2 was also obtained from Sigma-Aldrich. A CS solution (10 g/l) was prepared by dissolving CS in $2.3 \%(\mathrm{v} / \mathrm{v})$ aqueous acetic acid solution. $500 \mathrm{mg}$ of this CS solution and the different contents of BMP-2 $(0.75 \mu \mathrm{g} / \mathrm{ml}, 1 \mu \mathrm{g} / \mathrm{ml}, 1.25 \mu \mathrm{g} / \mathrm{ml})$ were mixed and then the crossliker was added (vanillin $1 \% \mathrm{v} / \mathrm{v}$ ethanol aqueous solution). The emulsified solution was immediately poured into the CS-BMP-2 mixture and stirred with a magnetic stirrer for $4 \mathrm{~h}$ so as to allow the solvent to evaporate. The hardened microspheres were then collected by centrifugation at $3000 \mathrm{rpm}$ for $3 \mathrm{~min}$, washed three times with distilled water, and lyophilized using a freeze dryer.

\section{Preparation of DBB/CMs scaffold}

Preparation of BMP-2-loaded CS microspheres on DBB scaffold surfaces was performed in the following process. In the first-step, DBB powders were radiofrequency (RF) plasma glow-discharged (PDC-32 G, Harrick Plasma, USA) in an oxygen-filled chamber at a pressure of $200 \mathrm{mTorr} \mathrm{Pa}$. The plasma power density and the treatment time were fixed at $30 \mathrm{~W}$ and $120 \mathrm{~s}$, respectively. Then the treated DBB powders were blended with different contents of chitosan microspheres solution and poured into a polystyrene mold, and frozen at $-20^{\circ} \mathrm{C}$ overnight. Finally, the composites were lyophilized with a freeze dryer to obtain the DBB/CMs scaffolds. 


\section{Characterization of materials}

XRD was used to determine the structure of the synthesized DBB. XRD measurements were performed with an X-ray diffractor [D/max-II; X-ray Diffractometer (XRD), RIGAKU, Japan] ( $\mathrm{Cu}-\mathrm{Ka})$. The samples were measured in the $2 \theta$ range from $10^{\circ}$ to $70^{\circ}$ (scan speed of $0.02^{\circ}$ per second).

The morphology of the obtained chitosan microspheres and DBB scaffolds was examined by a scanning electron microscopy (SEM, S-2400; Hitachi, Japan).

Chemical analysis of the DBB, CS and DBB/CMs materials was carried out by a Fourier transform infrared (FT-IR) spectrophotometer (FTIR 650) in the range from $4000 \mathrm{~cm}^{-1}$ to $400 \mathrm{~cm}^{-1}$ at a resolution of $3 \mathrm{~cm}^{-1}$, averaging 100 scans.

\section{In vitro release profile}

The quantification of the delivery profile of BMP-2 $(0.75 \mu \mathrm{g} / \mathrm{ml}, 1 \mu \mathrm{g} / \mathrm{ml}, 1.25 \mu \mathrm{g} / \mathrm{ml})$ from this system was determined using an enzyme-linked immunosorbent assay (ELISA) kit (PeproTech EC, London, UK) [17].

\section{In vitro study}

Mouse calvaria-derived, pre-osteoblastic cells MC3T3-E1 were cultured as monolayers in Alpha Minimum Essential Medium ( $\alpha$-MEM, GIBCO), supplemented with 10\% (v/v) fetal bovine serum (FBS; Sigma), 1\% (v/v) L-glutamine (Invitrogen Corp., Carlsbad, CA, USA), and a $1 \%(\mathrm{v} / \mathrm{v})$ antibiotic and antimycotic formulation (containing penicillin G sodium, streptomycin sulfate (Invitrogen Corp., Carlsbad, CA, USA). The medium was changed on alternate days, and the cultures were maintained at $37^{\circ} \mathrm{C}$ within a humidified atmosphere containing $5 \% \mathrm{CO}_{2}$.

When the confluence reached 90\%, the cells were passaged (P1). After passaging three times (P3), the cells were exposed to proliferation assays using CCK8 kits at 3d, $5 d, 7 d, 14 d$ to study the impact of BMP-2 on the multiplication of MC3T3 cells. The cells were assigned into BMP-2 groups $(0.75 \mu \mathrm{g} / \mathrm{ml}, 1 \mu \mathrm{g} / \mathrm{ml}, 1.25 \mu \mathrm{g} / \mathrm{ml})$ and a control group.

Each cell suspension $(5 \mathrm{ml})$ was plated at a density of $1 \times 10^{6}$ cells $\mathrm{ml}^{-1}$ in plates containing sterile samples of microsphere-scaffolds for the cell attachment assays. SEM micrographs were taken at 1 day following the initial cell co-culturing with the scaffolds. Briefly, the co-cultured constructs were harvested, washed with PBS and then fixed with $4 \%$ glutaraldehyde. Following 3 rinses with water, these samples were dehydrated through a series of graded alcohol solutions and then air-dried overnight. The samples were observed by SEM at an accelerating voltage of $30 \mathrm{kV}$ (QUANTA 250 FEG, USA).

\section{Differentiation of cells on microsphere-scaffold}

MC3T3-E1 cells were seeded with new medium. When the density reached $10 \%$ after 3 passages, about $1 \times 10^{6}$ cells were seeded on T25 flasks. Then these colonies were switched to an osteo-inducing medium (a-MEM, 10-8 M dexamethasone, $50 \mu \mathrm{g} / \mathrm{ml}$ ascorbic acid, $10 \mathrm{mM}$ ß-glycerophosphoric acid). The cells were assigned into a BMP-2 group and control group respectively. Samples from each group were collected at $3 \mathrm{~d}$ and $7 \mathrm{~d}$ for western blotting and real-time PCR analysis. 


\section{Western blotting}

MC-3 T3 cells were lysed in an RIPA buffer supplemented with protease inhibitors (\#11-10601, SinoGene Scientific, Beijing China) and phosphatase inhibitors (\#11-10701, SinoGene Scientific, Beijing China). Protein concentration was determined using the Bradford method. $30 \mu \mathrm{g}$ protein lysate was mixed with $2 \times$ loading buffer at 1:1 and heated for $10 \mathrm{~min}$ at $95^{\circ} \mathrm{C}$ before being loaded for gel electrophoresis.

The proteins and protein marker (SM1881, Thermo Fermentas) were separated by SDS-PAGE (4\% stacking gel, 12\% separating gel) at $120 \mathrm{~V}$ for $2 \mathrm{~h}$. Proteins were transferred to PVDF membranes using a Bio-rad mini transfer system. The membranes were blocked in rapid blocking Buffer (\#66-11402, SinoGene) for $5 \mathrm{~min}$ and then probed with primary antibodies against ALP, BMP-2, OST and RUNX2 at a dilution of 1:1000 for $2 \mathrm{~h}$. After washing 3 times with PBS, at $10 \mathrm{~min}$ per wash, HRP-conjugated anti rabbit and anti-mouse antibodies (10104, 10105, Miroanalysis Inc.) were applied to the membranes at a dilution of 1:2000 for $1 \mathrm{~h}$. Chemiluminescent signals were developed using a ECL Kit (ECL, 29050, Engreen) and exposed to X-ray films in a dark room. Then the membranes were stripped by a stripping buffer (\#66-11501, SinoGene Scientific) and reprobed with $ß$-actin (M20010, Ab-mart). The level of actin was measured as an internal control.

\section{Real-time PCR analysis}

Total RNA was isolated from samples using an SG TriEx HiPure RNA Extraction Kit (\#55-11120, SinoGene Scientific, China). RNA concentration was measured at $260 \mathrm{~nm}$ and its purity was assessed with Biophotometer (Eppendorf, Germany) at a ratio of 260:280 nm. RNA samples were treated with DNaseI (EN0523, Fermentas) to remove contaminating genomic DNA and analyzed on 1.5\% agarose gels. Reverse transcription was performed with a Thermo First cDNA Synthesis Kit (\#33-20102, SinoGene Scientific China) with random hexamer primers. The average amount of RNA used in the reverse transcription reaction was $1 \mu \mathrm{g}$ and its purity was around 2.0 (260:280 $\mathrm{nm}$ ratio).

qPCR per tube contained $10 \mu \mathrm{l}$ of $2 \times$ SG Green qPCR Mix (with ROX), (\#22-10102, SinoGene Scientific, China), $250 \mathrm{nM}$ of each primer (List of primers as Table 1), PCR grade water and $1 \mu \mathrm{l}$ of cDNA template (diluted in a 1:2 or 1:10 ratio). All samples were assayed in duplicates with each run. The PCR cycling program consisted of $10 \mathrm{~min}$ at $95^{\circ} \mathrm{C}$, followed

Table 1 Chain reaction primers used for detection in this study

\begin{tabular}{lll}
\hline Primers sequence & Target gene & Product size (bp) \\
\hline CGACAGCAAGCCAAGAG & ALP & 110 \\
GTGGAGACGCCCATACCA & & 132 \\
ACATCCGCTCCACAAACG & BMP-2 & \\
GGTGCCACGATCCAGTCA & & 129 \\
CTTCTCAGAGCCTCAGTCC & OCN & \\
ACCGTAGATGCGTTGTAG & & 136 \\
CTGGCGGTGCAACAAGAC & RUNX2 & \\
AACAGCGGAGGCATTTCG & & 125 \\
ACTCGCTGCGCTCGGTCGTT & ACTIN & \\
CCTITGGTGGCCTITGCTCAC & & \\
\hline
\end{tabular}


by 40 cycles of $15 \mathrm{~s}$ at $95^{\circ} \mathrm{C}$ and $60 \mathrm{~s}$ at $58^{\circ} \mathrm{C}$. An additional step was used $\left(95^{\circ} \mathrm{C}\right.$ for $15 \mathrm{~s}$, $58^{\circ} \mathrm{C}$ or $55^{\circ} \mathrm{C}$ for $30 \mathrm{~s}$ and $95^{\circ} \mathrm{C}$ for $15 \mathrm{~s}$ ) for dissociation curve analysis. Data were analyzed by 2-deltadelta $\mathrm{Ct}$ method; a statistical comparison between samples was performed using unpaired Student's $t$-test. A p value of $<0.05$ was considered statistically significant.

\section{Ethics statement}

All experiments involving the use of animals were incompliance with Provisions and General Recommendation of Chinese Experimental Animals Administration Legislation and were approved by Beijing Municipal Science \& Technology Commission (Permit Number: SCXK (Beijing) 2006-0008and SYXK (Beijing) 2006-0025).

\section{Statistical analysis}

Data is given as means \pm S.E.M. for statistical comparison, $t$-test or one-way ANOVA followed by Tukey's test was used." $\mathrm{p}<0.05,{ }^{* * *} \mathrm{p}<0.01$ and ${ }^{* * * *} \mathrm{p}<0.001$ were considered to be statistically significant.

\section{Results}

XRD measurement

The XRD pattern of DBB is shown in Figure 1. The XRD patterns of the DBB samples (Figure 1) are very similar to that of pure HA and TCP, and are in accordance with ASTM data (Card 84-1998 and 70-2005). All of the diffraction peaks were sharp and well resolved, indicating the two obtained phases.

\section{SEM of CMs}

The microspheres were spherical and had a regular surface (Figure 2). The particle size distribution was in the range of $9.634 \mu \mathrm{m}$, based on SEM observations. In this study, the vanillin concentration is crucial to the morphology of the microspheres. To prepare spherical microspheres with smooth surfaces, the vanillin concentration should be $1 \%$ so assist with crosslinking the CS molecules.

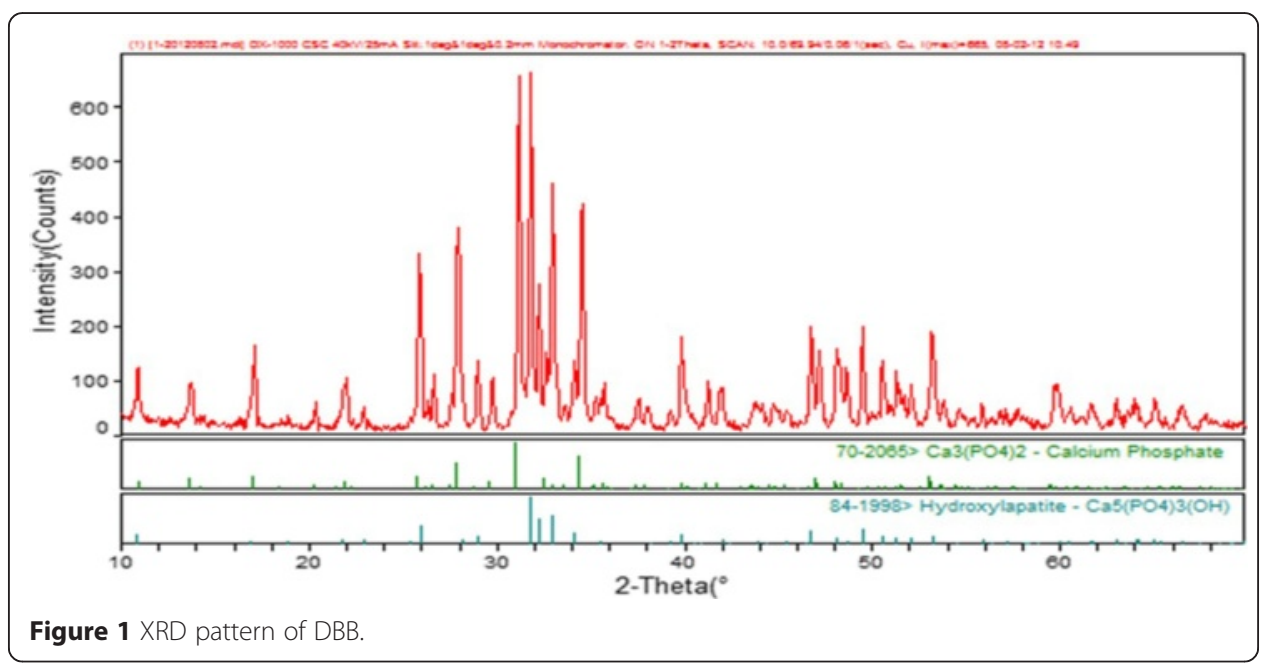



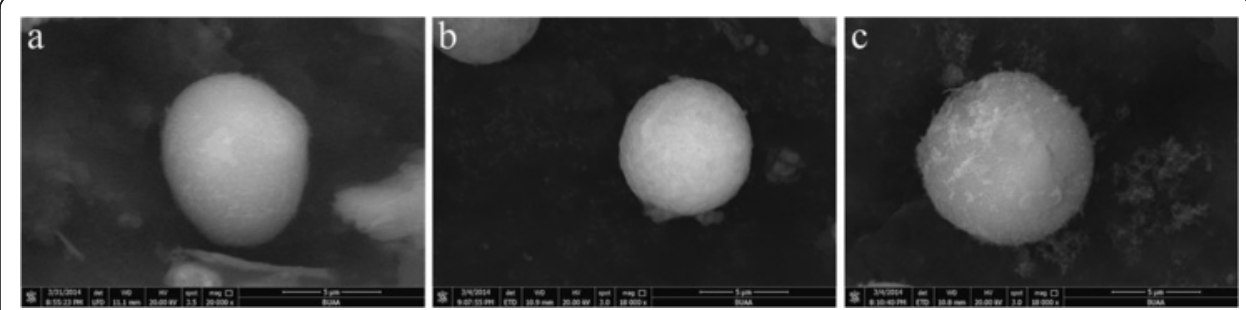

Figure 2 SEM of CMs (a: $1.25 \mu \mathrm{g} / \mathrm{ml} \mathrm{BMP-2;} \mathrm{b:} 1 \mu \mathrm{g} / \mathrm{ml} \mathrm{BMP-2;} \mathbf{c}: 0.75 \mu \mathrm{g} / \mathrm{ml} \mathrm{BMP-2}$ ).

The surface morphology and interconnectivity of the fabricated scaffolds were analyzed. Figure 3a presents a surface image of DBB showing a densely porous structure with good interconnectivity between the pores. After loading the CMs, the DBB/CMs/ BMP-2 scaffold presented smaller pores with reduced tunnel sizes for interconnectivity (shown in Figure $3 \mathrm{~b}$ ) than that of the pure DBB scaffold. It also demonstrated that DBB succeed loading the CMs. The pore size of the DBB scaffold was focused in the range from 300 to $400 \mathrm{~mm}$. However, as depicted in Figure 3b, the pore size of the DBB/ CMs/BMP-2 scaffold had a wider range from 80 to $300 \mathrm{~mm}$. This greater pore size distribution could affect cell-proliferation. The stability of the microspheres on the surface of DBB scaffold was shown in Figure 3c,d, respectively. SEM revealed the microspheres bonded with DBB by plasma modified. These immobilized microspheres help the release profile from microspheres immobilized on DBB scaffold surfaces.

\section{FT-IR analysis}

IR spectra of synthesized DBB, pure CS, and DBB/CMs/BMP-2 composite powders are shown in Figure 4a,b and c. The major DBB bonds, which are associated with $\mathrm{PO}_{4}{ }^{3-}$ (1035, 963 and $\left.604 \mathrm{~cm}^{-1}\right)$ and $\mathrm{OH}^{-}\left(3571 \mathrm{~cm}^{-1}\right)$, are apparent in Figure 4c. IR spectra show that there were some changes in the frequencies of $\mathrm{PO}_{4}{ }^{3-}$ and $\mathrm{OH}^{-}$, which shift

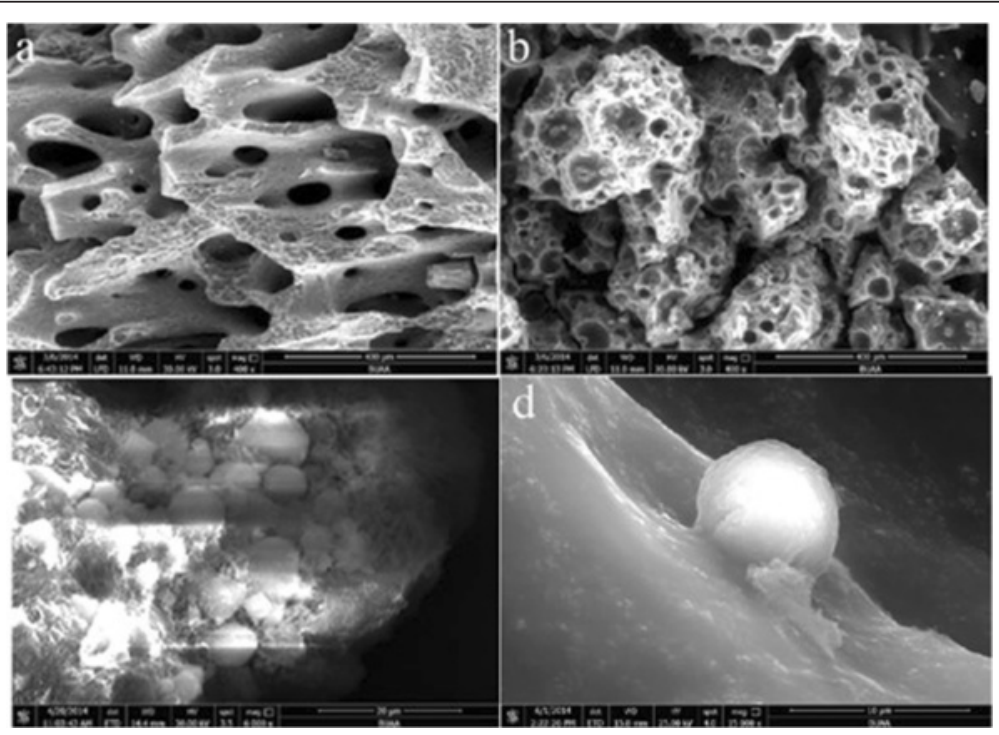

Figure 3 SEM of DBB (a: amplified $\times 400)$ and DBB/CM/BMP-2 composite scaffold (b: amplified $\times 600$; c: amplified $\times 4000$; d: amplified $\times 15000$ ). 
to low wave numbers in the composite. In addition, the bonds of $\mathrm{CO}_{3}{ }^{2-}$ (1422 and $\left.1484 \mathrm{~cm}^{-1}\right)$ and $\mathrm{HPO}_{4}^{-}\left(871 \mathrm{~cm}^{-1}\right)$ also appear in the spectra (Figure $4 \mathrm{a}$ and $\mathrm{d}$ ). These ions also show up in natural bone apatite, called non-stoichiometric apatite.

In Figure 4b, the characteristic peaks of pure CS are displayed at $1655 \mathrm{~cm}^{-1}$, which can be assigned to the absorption of amide I carbonyl stretching, while the peak of carbonyl stretching shifted to $1643 \mathrm{~cm}^{-1}$ in Figure 4c. This change signifies interaction between CS and DBB.

\section{Release testing}

Figure 5 shows the in vitro release profiles of encapsulated BMP-2 from CS microspheres loaded on the DBB scaffold. An early burst of approximately $19 \%$ of the total BMP-2 can be seen after being loaded for $24 \mathrm{~h}$, followed by a sustained release of the remaining BMP-2 over the next 7 days. The experimental data curve indicates that the BMP-2 release behavior might be attributed to both a reaction-controlled mechanism and diffusion-controlled mechanism. Thus, this synthesized DBB/CMs/BMP-2 system would allow for intercelluar release of the drug with high local concentrations at the site of interest.

\section{Attachment and proliferation of cells on DBB/CMs/BMP-2 scaffold}

SEM images displaying the morphological features of pre-osteoblastic cells MC3T3-E1 cultured on the bone particles for $24 \mathrm{~h}$ are shown in Figure 6. The cells were observed to spread well and had intimate contact with the inner surface of the scaffold (Figure 6a). Upon examining the scaffolds at an increased depth, the cells could be seen to adhere tightly to the crystalline structure of the bone, with aggregated cells being clustered along the pore walls of the scaffolds (Figure $6 \mathrm{~b}$ ).

A CCK-8 assay was used to evaluate the cytotoxicity of the CMs- scaffold, and the OD values can provide an indication of cell growth and proliferation on various materials. As seen in Figure 7, the OD values for the BMP-2 scaffold increased with culture duration, which indicates that this particular scaffold had no detrimental effect on the

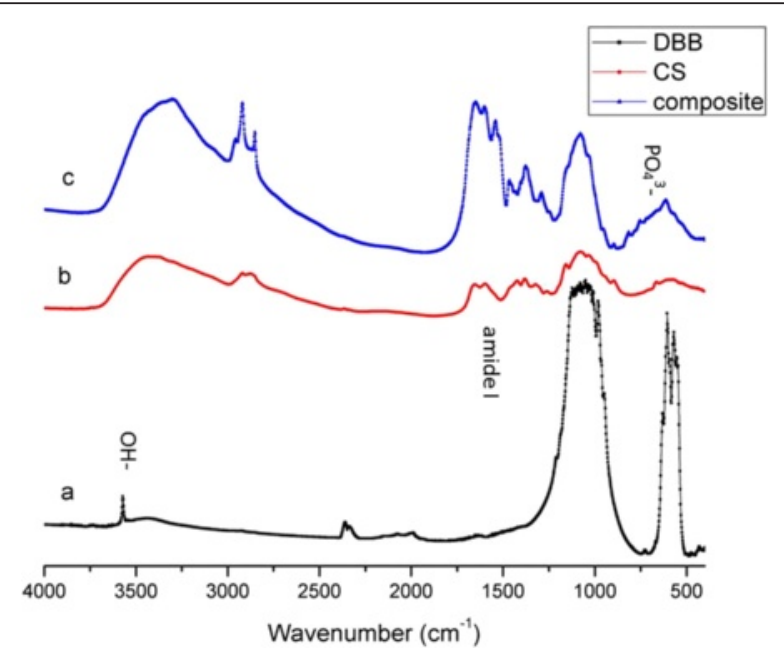

Figure 4 FT-IR of CMs (a: DBB; $\mathbf{b}:$ CS; $\mathbf{c}$ : DBB/CMs/BMP-2 composite). 


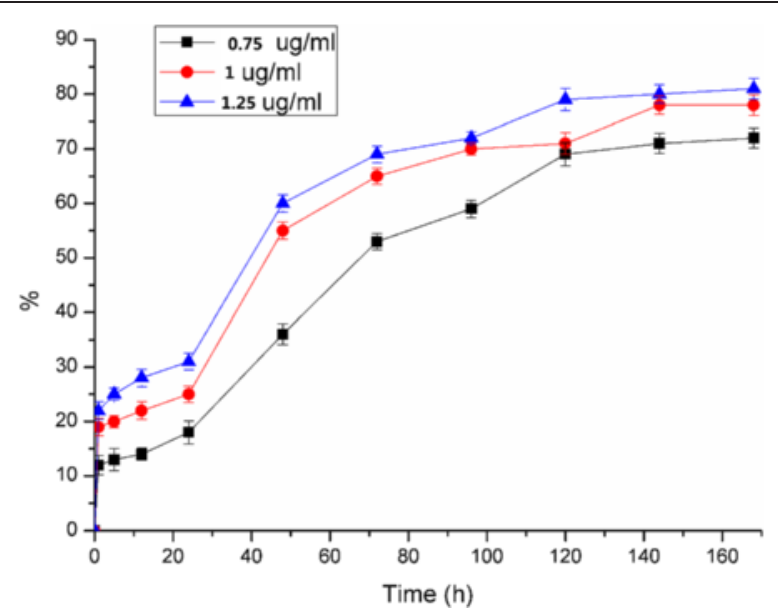

Figure 5 Release profile for BMP-2 from DBB/CMs/BMP-2 scaffolds in PBS within 7 days.

viability and proliferation of MC3T3-E1 cells, thus demonstrating good biocompatibility. In addition, this trend suggested that increasing BMP-2 concentration promote cell proliferation in these 7 days.

\section{Differentiation of cells on CMs- scaffold}

Histochemical analyses revealed strong osteogenic properties for the BMP-2 containing CM scaffold. In order to further confirm the differentiation of MC3T3-E1 cells, the expression of ALP, BMP-2, OCN and RUNX2 was analyzed at the 3rd day and the 7th day after culturing on induced medium by western blot (Figure 8). Inductions of osteoblast specific genes ALP, BMP-2, OCN, and RUNX2 were examined by RT-PCR (Figure 9). The results of qPCR were consistent with the WB analysis, which showed that the expressions of OCN, ALP and BMP-2 were increased in contrast with the CON group. The foldchange of gene expression in the BMP-2 treatment data is shown in Table 2.

Osteoblast cells were noted to proliferate on the materials on day 7 of culture; and the osteoblasts in the $\mathrm{DBB} / \mathrm{CMs}$ scaffold without BMP-2 showed a lower increase on the 7th day of culture compared with those cultured on the other days. In contrast, cells growing on the DBB/CMs/BMP-2 scaffold did not show an increased tendency for proliferation at the same time point either with BMP-2. According to the data of the proliferation assay, the osteoblast cells in the DBB/CMs/BMP-2 scaffold had higher proliferation rates within 7 days than the controls, which indicated that the BMP-2 promoted cell proliferation. The osteoblast cells in this novel drug delivery system reached the end of first period faster than the control, which implied that the applied BMP-2 was beneficial to the osteoblast cells' differentiation as well. Hence, Figure 9 not only shows the tendency for osteoblast proliferation induced by the drug delivery scaffold with or without BMP-2, but also indirectly reflects osteoblast differentiation.

\section{Discussion}

The main objective of this study was to investigate BMP-2/CMs scaffolds as potential dual-drug/protein delivery systems for slow and sustained delivery of different bioactive 

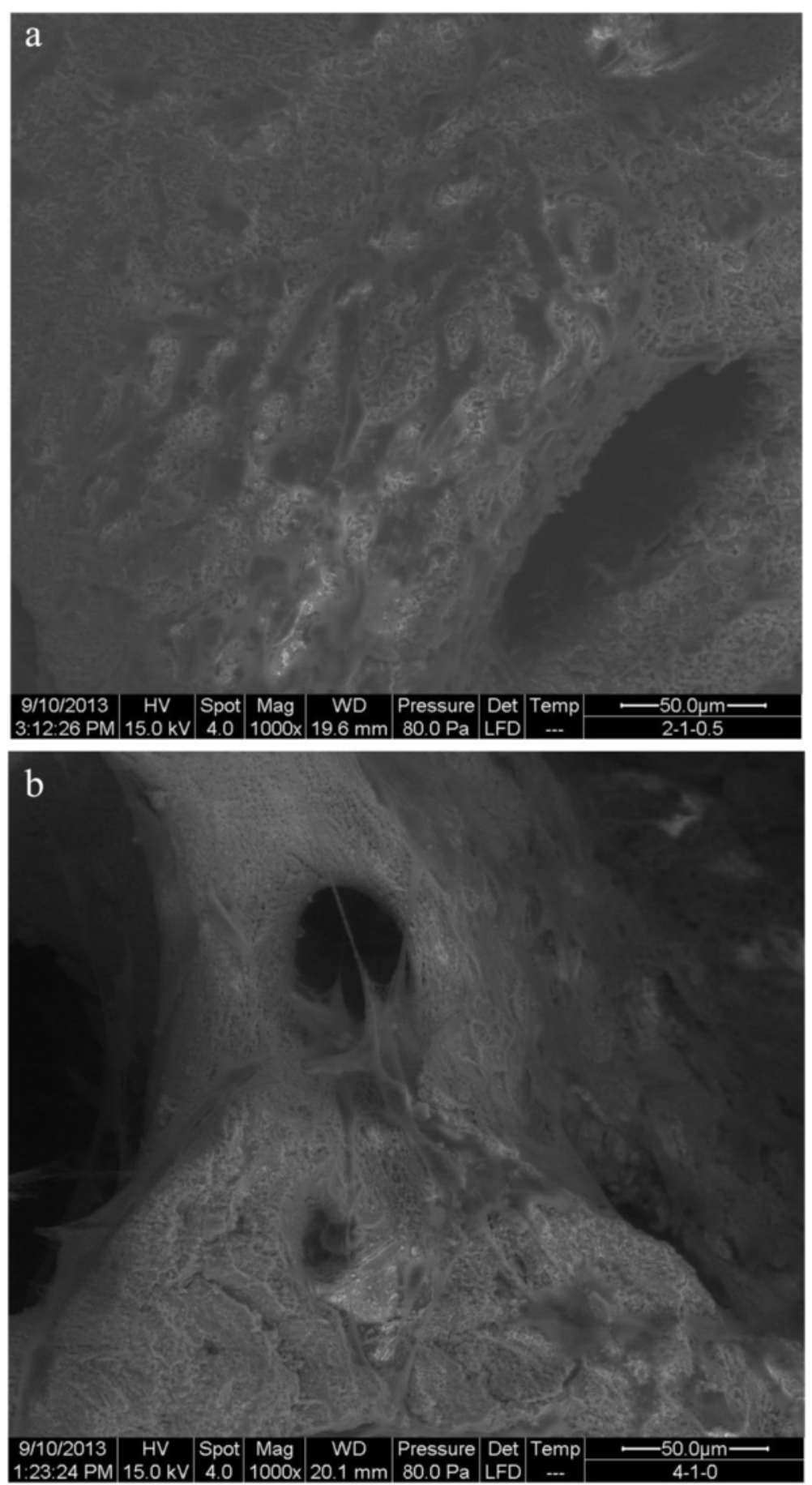

Figure 6 SEM of cell growth on the material surface (a: control without BMP-2; $\mathbf{b}$ : DBB/CMs/BMP-2 scaffold).

agents. The retrieved data confirmed that a gradual, sustained, and cell-mediated release of bioactive agents can be achieved in vitro using a BMP-2/CMs scaffold. Moreover, the DBB/CMs scaffold loaded with BMP-2 showed excellent osteoinductivity.

In designing a matrix for differentiation factor release, it is apparent that the extremes of release (bolus injections or prolonged low level release) are not beneficial to 


\section{BMP2}

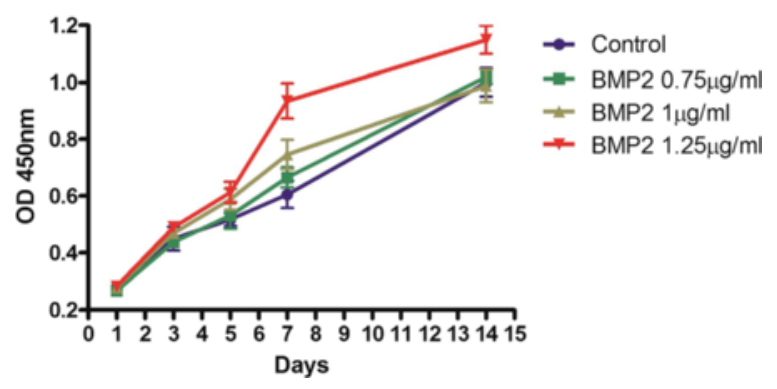

Figure 7 The proliferation of cells on CMs- scaffold with BMP-2.

bone induction. A further complicating factor is that different anatomical sites might require different kinetics of release for optimal performance. For example, in more fluid environments or compromised (avascular) sites, BMP clearance might be faster than the bone-induction response of the host. In these cases a slow-release system may be required. It has been suggested that bone repair therapy is influenced not just by the amount of protein present but also by the duration of protein production. So an important issue when accessing growth factors for local bone repair is to identify an ideal drug delivery carrier which can ensure a sufficient protein concentration and effect at the application site for the duration of the healing process, and therefore provide an appropriate support for bone repair. In the current study, the BMP-2 release resulted in a gradual, sustained protein release pattern. Further investigations are needed to analyze the in vivo release of BMP-2.

The degradability of CaP-based materials is very important for the in vivo longevity and efficacy of its biological effects. The findings of this study indicate that CMs scaffolds are degradable and both in vitro and in vivo results indicate that the coating can

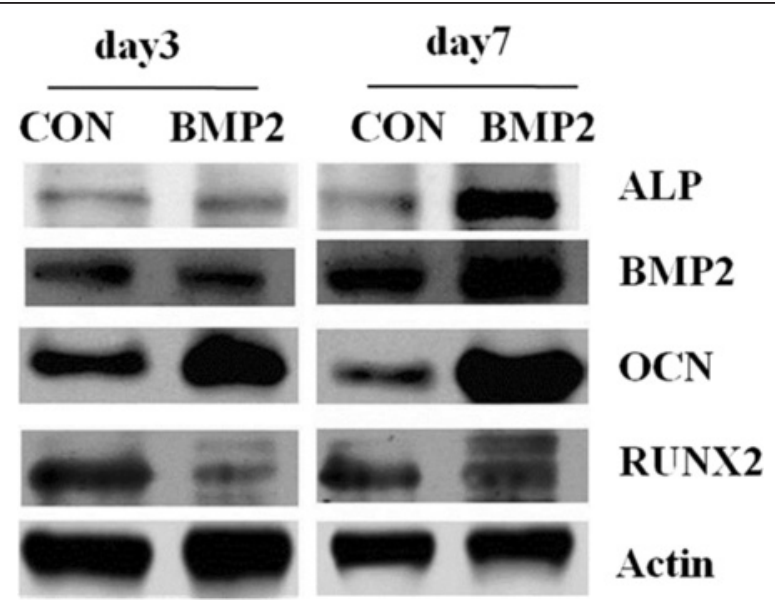

Figure 8 On the 3rd day, the expression levels of OCN and ALP were increased and RUNX2 was decreased in contrast with the control group, while the expression of BMP-2 had no significant difference between the two groups. On the 7th day, the expressions of ALP, OCN, BMP2 had increased and the expression of RUNX2 had decreased in both the control and BMP-2 group compared with their expression status on the third day. 


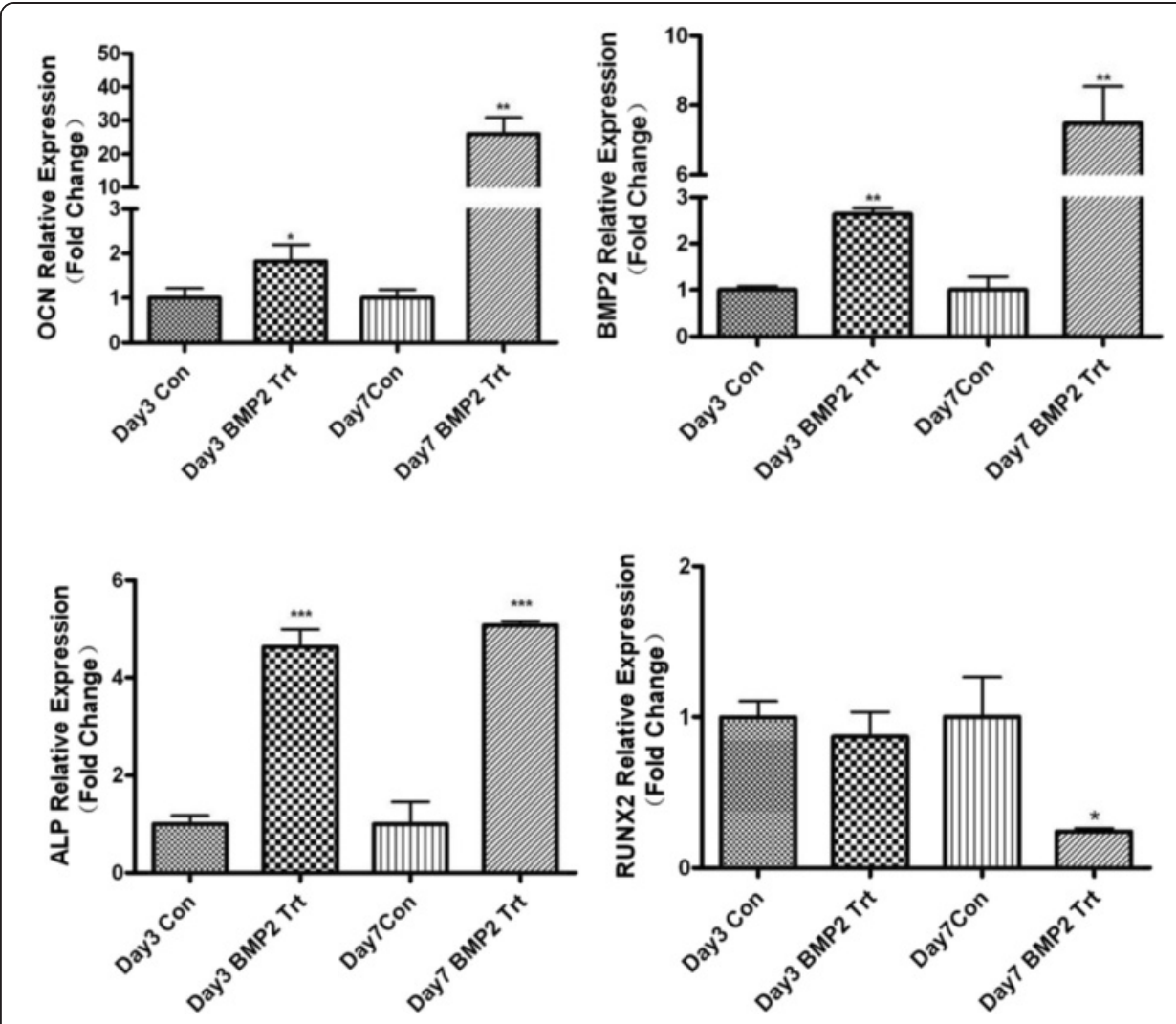

Figure 9 Compared the control group, on the 3rd day and the 7th of treatment, expression levels of genes OCN, BMP-2 and ALP increased ( $p<0.05)$. RUNX2 genes were observed to decrease.

prevent and delay the degradation of underlying Bio-CaP, even though the coating is biodegradable.

The coating and Bio-CaP were all biomimetically formed by precipitation of calcium phosphate. However, their surface structures were totally different before coating. It was demonstrated that BMP-2 incorporated into biomimetic coatings can retain its biological activity and that the growth factors released through osteoclastic activity could significantly promote osteoblastogenesis in vitro. Therefore, we assume that BMP-2 maintains its activity. However, further investigations are needed to prove the specific activity of BMP-2.

In bone tissue engineering, osteoblast cells are one of the most crucial factors that lead to the ultimate formation of new bone tissue. The ECM proteins function as a substratum for bone cell adhesion and serve as a scaffold for mineralization [18]. In the current work, the constructs of the CMs scaffold drug delivery system of DBB/CMs/ BMP-2 were observed with SEM after culturing with an osteogenesis-inducing medium for 7 days (Figure 6). In general, cells growing on the DBB/CMs scaffold revealed many typical globular round cells which integrated with the scaffold. In particular, the DBB/ CMs/BMP-2 group showed that the cells growing on this material were surrounded by a thick substance. The reason is that the BMP-2 produced many substances on the surface of the original scaffold, which assisted the osteoblasts growth. Besides, BMP-2 also assisted the proliferation tendency of the osteoblasts induced by the drug delivery scaffold (Figures 8 and 9). 
Table 2 Fold-change of different gene expressions after BMP-2 treatment

\begin{tabular}{lllll}
\hline & Day3 CON & Day3 Trt & Day 7 CON & Day 7 Trt \\
\hline ALP & $1 \pm 0.1716$ & $4.637 \pm 0.3565^{* * *}$ & $1.003 \pm 0.4517$ & $5.077 \pm 0.08647^{* * *}$ \\
BMP-2 & $1 \pm 0.08$ & $2.64 \pm 0.13^{* *}$ & $1 \pm 0.2894$ & $7.483 \pm 1.058^{* *}$ \\
OCN & $1.003 \pm 0.2128$ & $1.823 \pm 0.3724^{*}$ & $1 \pm 0.1856$ & $25.94 \pm 4.835^{* *}$ \\
RUNX2 & $0.9967 \pm 0.1073$ & $0.87 \pm 0.1626$ & $1 \pm 0.2649$ & $0.2404 \pm 0.02242$ \\
\hline
\end{tabular}

***P $<0.001, * * P<0.01, * P<0.05$.

Our findings strongly suggest that this CMs scaffold can be used as an effective protein delivery vehicle. In addition, the use of the coating can offer an alternative for slow release. CMs scaffolds can offer a dual-release system for a sequential delivery of different proteins/drugs. This combination could be applicable for a variety of clinical applications. For example, osteogenic agents can be incorporated into the interior of CMs scaffolds, and at the same time, antibiotics can be incorporated into the surface coating. This could be considered as a new strategy for the treatment of bone defects caused by peri-implantitis. In conclusion, it was shown that the CMs scaffold with an internal or surface-coated depot of protein has the capacity to maintain a slow and sustained protein release in the presence of osteoclasts in vitro. Further investigations are needed to prove the in vivo release and actual activity of BMP-2. The dual-drug release system offers a promising tool for the controlled delivery of multiple therapeutic agents, such as antibiotics, osteogenic agents, and anti-cancer drugs for different clinical applications.

\section{Conclusions}

A functional scaffold loading microspheres system was successfully developed and shown to be an excellent drug delivery platform for bone regeneration. BMP-2 as a model bioactive molecule was efficiently added to the microsphere-loading DBB scaffold with perfect biocompatibility, and offered efficient release kinetics of BMP-2. Therefore, this novel CS microsphere-loaded DBB scaffold system may be applicable as a promising scaffold for bone regeneration.

Competing interests

The authors declare that they have no competing interests.

\section{Authors' contributions}

QL and GZ were the principal investigators of this study. They made substantial contributions to conception and design, as well as the acquisition, analysis and interpretation of data; ZT were involved in drafting the manuscript or revising it critically for important intellectual content, and gave final approval of the version to be published. XY, TW and YX made substantial contributions in acquisition of data and participated in drafting the manuscript and helped in the revision of the manuscript. All authors read and approved the final manuscript.

\section{Acknowledgements}

This study was supported by funds from Capital Public Health Project (z2110005312001), NSFC Research Grant (11002016, 11120101001,10925208, 61227902), National Basic Research Program of China (973 program, 2011CB710901), National Key Technology R\&D Program (No. 2012BAl18B06, 2012BAl18B05), the 111 Project of China (No. B13003), International Joint Research Center of Aerospace Biotechnology.

\section{Author details}

${ }^{1}$ Center of Digital Dentistry, Peking University School and Hospital of Stomatology, 22 Zhongguancun Nandajie, Haidian District, Beijing 100081, China. ${ }^{2}$ National Engineering Laboratory for Digital and Material Technology of Stomatology, 22 Zhongguancun Nandajie, Haidian District, Beijing 100081, China. ${ }^{3}$ Key Laboratory for Biomechanics and Mechanobiology of Ministry of Education, School of Biological Science and Medical Engineering, Beihang University, Beijing 100191, China. 
Received: 16 October 2014 Accepted: 30 March 2015

Published online: 15 April 2015

\section{References}

1. Shang F, Ming L, Zhou Z, Yu Y, Sun J, Ding Y, et al. The effect of licochalcone A on cell-aggregates ECM secretion and osteogenic differentiation during bone formation in metaphyseal defects in ovariectomized rats. Biomaterials. 2014;35:2789-97.

2. Thormann U, Ray S, Sommer U, Elkhassawna T, Rehling T, Hundgeburth M, et al. Bone formation induced by strontium modified calcium phosphate cement in critical-size metaphyseal fracture defects in ovariectomized rats. Biomaterials. 2013;34:8589-98.

3. Meyer Jr RA, Tsahakis PJ, Martin DF, Banks DM, Harrow ME, Kiebzak GM. Age and ovariectomy impair both the normalization of mechanical properties and the accretion of mineral by the fracture callus in rats. J Orthop Res. 2001;19:428-35.

4. Namkung-Matthai H, Appleyard R, Jansen J, Hao Lin J, Maastricht S, Swain M, et al. Osteoporosis influences the early period of fracture healing in a rat osteoporotic model. Bone. 2001;28:80-6.

5. Fairbairn NG, Randolph MA, Redmond RW. The clinical applications of human amnion in plastic surgery. J Plast Reconstr Aesthet Surg. 2014;67:662-75.

6. Chen Z, Wu C, Gu W, Klein T, Crawford R, Xiao Y. Osteogenic differentiation of bone marrow MSCs by beta-tricalcium phosphate stimulating macrophages via BMP2 signalling pathway. Biomaterials. 2014;35:1507-18.

7. Muller KH, Motskin M, Philpott AJ, Routh AF, Shanahan CM, Duer MJ, et al. The effect of particle agglomeration on the formation of a surface-connected compartment induced by hydroxyapatite nanoparticles in human monocyte-derived macrophages. Biomaterials. 2014;35:1074-88.

8. Van Manen EH, Zhang W, Walboomers XF, Vazquez B, Yang F, Ji W, et al. The influence of electrospun fibre scaffold orientation and nano-hydroxyapatite content on the development of tooth bud stem cells in vitro. Odontology. 2014;102:14-21.

9. Wiltfang J, Jatschmann N, Hedderich J, Neukam FW, Schlegel KA, Gierloff M. Effect of deproteinized bovine bone matrix coverage on the resorption of iliac cortico-spongeous bone grafts - a prospective study of two cohorts. Clin Oral Implants Res. 2014;25:e127-32.

10. Garcia EV, Valdecantos PA, Barrera D, Roldan-Olarte M, Miceli DC. Bone morphogenetic proteins in the bovine oviduct: differential expression of BMP-5 in the isthmus during the estrous cycle. Theriogenology. 2014;81:1032-41.

11. Rahman CV, Ben-David D, Dhillon A, Kuhn G, Gould TW, Muller R, et al. Controlled release of BMP-2 from a sintered polymer scaffold enhances bone repair in a mouse calvarial defect model. J Tissue Eng Regen Med. 2014;8:59-66.

12. Imamura K, Maeda S, Kawamura I, Matsuyama K, Shinohara N, Yahiro Y, et al. Human immunodeficiency virus type 1 enhancer-binding protein 3 is essential for the expression of asparagine-linked glycosylation 2 in the regulation of osteoblast and chondrocyte differentiation. J Biol Chem. 2014;289:9865-79.

13. Almodovar J, Guillot R, Monge C, Vollaire J, Selimovic S, Coll JL, et al. Spatial patterning of BMP-2 and BMP-7 on biopolymeric films and the guidance of muscle cell fate. Biomaterials. 2014;35:3975-85.

14. Allouche FN, Guibal EE, Mameri N. Preparation of a new chitosan-based materials and its application for mercury sorption. Colloids Surf A Physicochem Eng Asp. 2014;446:224-32.

15. Abdelgawad AM, Hudson SM, Rojas OJ. Antimicrobial wound dressing nanofiber mats from multicomponent (chitosan/silver-NPs/polyvinyl alcohol) systems. Carbohydr Polym. 2014;100:166-78.

16. Ferrand A, Eap S, Richert L, Lemoine S, Kalaskar D, Demoustier-Champagne S, et al. Osteogenetic properties of electrospun nanofibrous PCL scaffolds equipped with chitosan-based nanoreservoirs of growth factors. Macromol Biosci. 2014;14:45-55.

17. Liu Y, De Groot K, Hunziker EB. BMP-2 liberated from biomimetic implant coatings induces and sustains direct ossification in an ectopic rat model. Bone. 2005;36:745-57.

18. Meng J, Zhang $Y$, Qi X, Kong H, Wang C, Xu Z, et al. Paramagnetic nanofibrous composite films enhance the osteogenic responses of pre-osteoblast cells. Nanoscale. 2010;2:2565-9.

\section{Submit your next manuscript to BioMed Central and take full advantage of:}

- Convenient online submission

- Thorough peer review

- No space constraints or color figure charges

- Immediate publication on acceptance

- Inclusion in PubMed, CAS, Scopus and Google Scholar

- Research which is freely available for redistribution

Submit your manuscript at www.biomedcentral.com/submit 